\title{
La fragilidad de la mujer guerrillera reclutada forzosamente
}

\author{
Daniela Echeverri Guzmán* \\ (dannyecheverri@gmail.com)
}

Artículo corto recibido el 2/10/2015 aprobado el 19/11/2015.

Cómo citar este artículo:

ECHEVERRI GUZMÁN, Daniela (2015). "La fragilidad de la mujer guerrillera reclutada forzosamente”. En: Trans-pasando Fronteras, Núm. 8, pp. 95-110. Cali, Colombia: Centro de Estudios Interdisciplinarios, Jurídicos, Sociales y Humanistas (CIES), Facultad de Derecho y Ciencias sociales, Universidad Icesi.

DOI: $10.18046 /$ retf.i8.2123

\begin{abstract}
Resumen
Este ensayo tiene como propósito dar a conocer la realidad de las mujeres que han sido reclutadas forzosamente para hacer parte de los frentes de las FARC a partir de una reflexión de los desafíos éticos que esto supone en el marco del actual proceso de paz en Colombia. Muchas de estas mujeres son objeto de violaciones y agresiones lo cual las delimita como víctimas del conflicto armado. Esto puede interpretarse como una contradicción en la ideología inicial del grupo revolucionario, que además da cuenta de los daños físicos y psicológicos, y los problemas éticos que existen a la hora de tomar decisiones para el posconflicto. El ensayo incluye un breve marco histórico de la guerrilla, luego expone la situación de algunas mujeres y las violaciones de las que son objeto, y finalmente, presenta un análisis desde una perspectiva ética, que permita entender el dilema de las mujeres en los frentes y la contradicción que este representa.
\end{abstract}

* $\quad$ Estudiante de Ciencia Política de la Universidad Icesi 
Palabras clave

Conflicto armado, problema ético, mujeres, violación de derechos humanos, FARC-EP.

\section{Introducción}

Colombia es un país cuya historia ha estado atravesada por el narcotráfico y la violencia. De hecho, el fenómeno del conflicto armado ha estado presente desde hace más de 50 años y aún continúa siendo una realidad. Esto ha determinado la forma en que se ha configurado la sociedad colombiana y a su vez, ha desencadenado inestabilidad y terror por los múltiples enfrentamientos, víctimas y violaciones de derechos humanos a lo largo de los años. Para nadie es un secreto que Colombia durante el siglo XX vivió uno de los momentos más tortuosos y complejos de su historia; la inestable situación política del país, caracterizada por un territorio fragmentado; la inconformidad de la población; y las disputas entre partidos por el control del Estado, dieron paso a la época de La Violencia. Este es un capítulo triste que termina con el Frente Nacional, pero deja restos de guerrillas campesinas, a partir de las cuales se configura el movimiento insurgente que ha atormentado al país desde entonces. Las Fuerzas Armadas Revolucionarias de Colombia -Ejército del Pueblo (FARC-EP, o sólo FARC)- surgen en este escenario como un proyecto revolucionario, al igual que otras guerrillas en la periferia y grupos paramilitares.

La presencia de diferentes grupos subversivos complejizaron el conflicto, y aumentaron la dificultad que erradicarlo implica. A pesar de que varios movimientos han ido desapareciendo con los años, otros han consolidado una organización fuerte y han perdurado, como es el caso de las FARC. Actualmente, el gobierno adelanta un proceso de paz con este grupo al margen de la ley a través de una serie de diálogos donde se pretende llegar a un acuerdo y finalmente lograr acabar con la guerra a la que el país ha estado sometido. Muchos son los retos que estas discusiones enfrentan, no sólo por la trayectoria de los enfrentamientos, sino por todas las aristas que se deben tener en cuenta. La solución más allá de ser entre las FARC y el Estado, involucra una serie de puntos que incluyen la reparación de las víctimas, la justicia transicional y la dejación de las armas, entre otros.

Esto complica el camino hacia la paz y pone de manifiesto los desafíos éticos del conflicto en sí mismo, en el marco de las terribles violaciones de los derechos 
humanos ${ }^{1}$ ocurridas. Por esta razón, la ética juega un papel crucial en el proceso de construcción de paz, dada la multiplicidad de actores involucrados y su participación en el conflicto armado; las transgresiones de derechos fundamentales y el problema de juzgar a los implicados. Así pues, de acuerdo a Diana Cohen, "la ética es la reflexión sobre el conjunto de conductas y normas imperantes en la sociedad y, por extensión, es la reflexión sobre cómo conducir nuestra vida" (Cohen, 2011: 15). Por lo tanto, en cada situación de la vida cotidiana en la que se debe tomar una decisión (en especial en cuestiones morales) la ética está presente invitando a una actitud reflexiva que conjugue nuestras emociones, valores y razones. Esto, porque a la hora de actuar hay que tener presente que somos parte de una sociedad y que aquello que hacemos puede afectar a los otros. Así, evaluar las consecuencias de nuestros actos sobre los demás, en el momento de tomar una elección, garantizaría el bienestar de todos los individuos y la consecución de uno de los principales objetivos de la ética: la felicidad.

Bajo este orden de ideas, la sociedad indiscutiblemente necesita de la ética para asegurar una convivencia sana y a su vez, evitar el comportamiento inmoral de los ciudadanos que la componen. No en vano muchos pensadores como Kant, Rawls y Habermas han estudiado las distintas formas de justicia y moral en la sociedad. Sin embargo, construir una teoría ética que asegure una actuación moralmente correcta de los individuos es inmensamente complejo y esto se ve reflejado en las falencias del mundo actual. De hecho se ve en nuestro entorno inmediato, pues ahora en medio del proceso de paz han salido a relucir varios interrogantes sobre el papel de las víctimas y los victimarios, la reparación de estas y las formas de justicia, entre otros. Esto ha dado lugar a debates y reflexiones sobre la guerra, y los conflictos éticos que las violaciones de derechos, las circunstancias del combate y los daños en los ciudadanos suponen. Es por esto, que el presente trabajo analiza el problema de las mujeres que son reclutadas forzosamente a los frentes de las FARC desde un enfoque ético. Esto implica una reflexión sobre el papel que juegan en el conflicto y las violaciones de las que han sido objeto, de manera que se pone en tela de juicio la ética del grupo guerrillero, la forma en que su ética ha sido coaccionada y la ética de los colombianos a la hora de juzgar a estas mujeres.

1 "Los derechos iguales e inalienables de todos los miembros de la familia humana" (Naciones Unidas, 1948). 
Siguiendo esta línea, posiblemente uno de los grupos sociales que en mayor medida ha sido víctima de los abusos de la guerra es el de las mujeres reclutadas forzosamente. Es importante comprender entonces que la palabra "víctima" hace referencia a toda persona que ha sufrido daños (físicos, psicológicos, morales, socioculturales, políticos, etc.) por medio de un agente externo que han alterado su identidad y cuyos derechos humanos fundamentales han sido vulnerados. Las víctimas tienen una dimensión pasiva en donde son receptoras de la agresión, y tienen también una dimensión activa cuando denuncian el daño que han sufrido y piden justicia. Por otro lado, la palabra "victimario o victimaria" corresponde a aquellas personas que realizan un daño sobre otra. En este sentido, los victimarios se convierten en el agente externo que perjudica a la víctima (CNRR-Grupo de Memoria Histórica, 2011). De esta forma, el posible caracterizar a estas mujeres como víctimas y a los guerrilleros como victimarios. Lo anterior, porque han sido forzadas a formar parte de la guerra y han sido objeto de violaciones y abusos. Algunas son sacadas de sus casas y obligadas a formar parte del grupo guerrillero, y otras han terminado en los frentes porque sus padres no pueden sostenerlas y las entregan a las FARC. En ambos casos ellas han tenido que ingresar por fuerza mayor, es decir que no han decidido por voluntad propia su destino, sino que un agente externo las ha condicionado a esa vida.

Sin embargo, el papel de las mujeres en las FARC tiene otra cara; también están aquellas que voluntariamente han decidido vincularse y ser un combatiente más. Ya sea porque esa es su única opción de alimentación y subsistencia, porque están enamoradas de algún guerrillero o porque simplemente quieren unirse, ellas terminan envueltas en la vida del monte y los fusiles. Es importante exponer esta distinción porque esta constituye las dos facetas de las mujeres en la guerrilla. Por un lado están aquellas mujeres cuyos derechos han sido violentados y que por lo tanto se convierten en víctimas del conflicto, y por otro lado están aquellas que cumplen un rol activo como agentes del movimiento. Esto porque no se puede negar la existencia de mujeres poderosas, que se han ganado el respeto de los hombres y han alcanzado un alto cargo dentro de los bloques, representando ahora el papel de victimarias.

Lo anterior nos lleva entonces a reflexionar sobre la situación de las mujeres que terminan en las FARC por medio del reclutamiento forzoso y cuestionarnos ¿de qué manera los derechos de estas mujeres son violados y cómo esto representa un problema ético y una con- 
tradicción dentro de su ideología política? Para responder esto, se utilizan historias reales de mujeres que relatan las circunstancias a las que se enfrentan en el grupo revolucionario y las formas como son abusadas y maltratadas. Así, este ensayo pretende dar cuenta de la realidad de las mujeres en las FARC, y a partir de una reflexión crítica demostrar que esta realidad refuta los ideales iniciales de la revolución y configura un desafío ético en términos de violación de derechos humanos. Para esto, primeramente se presenta un breve marco histórico que da cuenta de la conformación y primeros postulados de la guerrilla, luego se expone la situación de las mujeres y las violaciones de las que son objeto, y finalmente, se realiza un análisis desde una perspectiva ética, que permita entender el dilema de las mujeres en los frentes y la contradicción que este representa.

\section{El pasado de las FARC}

Determinar exactamente cuándo comenzó el conflicto armado en el país es difícil, sin embargo se puede establecer que este se remonta hasta la época de La Violencia. En efecto, el sociólogo y periodista Alfredo Molano afirma que "El conflicto armado comienza con la Violencia. Y la Violencia está asociada a dos factores originarios que se influyen mutuamente: el control sobre la tierra y sobre el Estado" (Molano, 2015: 541). La eterna lucha entre liberales y conservadores, tiene su punto culminante durante el periodo denominado como La Violencia, que data desde 1946 hasta $1965,{ }^{2}$ tiempo en que el enfrentamiento alcanza altos niveles de desorden público y coacción. Esto fue fruto del impacto de las reformas liberales del 30, que buscando modernizar el país desencadenaron divisiones en el gobierno e inestabilidad y que terminaría de estallar con el asesinato de Gaitán en 1948. Con la caída del representante de las aspiraciones populares (Molano, 2015), se configuran entonces una serie de movimientos campesinos que polarizó aún más el país en centro y periferia, el campo se convirtió en escenario de batalla entre conservadores y liberales, y las guerrillas campesinas se convirtieron en actores de la lucha. Todo este embrollo político, junto con el fracaso de la reforma agraria y los conflictos por la tierra escalarían el combate hacia una violencia no sólo política sino también social (PNUD, 2003).

2 Aunque muchos autores difieren en las fechas exactas, se contemplará este periodo específico, establecido en el Informe Nacional de Desarrollo Humano en Colombia - 2003 del Programa de las Naciones Unidas para el Desarrollo. 
Las FARC emergen en medio de este contexto y se posicionan inicialmente como un grupo de autodefensa campesina. Posteriormente, influenciados por el Partido Comunista conforman una guerrilla que evolucionaría hasta convertirse en un ejército revolucionario consolidado con la ocupación de Marquetalia, la formación del Bloque Sur y la adopción del Programa Agrario en 1964. En mayo del siguiente año se crean oficialmente las Fuerzas Armadas Revolucionarias de Colombia en la conferencia en el río Duda, donde además se designó a Manuel Marulanda comandante en jefe por elección de los 250 delegados que asistieron (Molano, 2015: 580). Todo esto es producto de los remanentes del Frente Nacional, la inconformidad de las personas por la injusticia social y la situación agraria del país, conjugado con el contexto de América Latina que presenciaba el apogeo de la ideología cubana, nicaragüense y bolivarista, lo cual termina de darle forma al grupo.

Se convierten en un ejército organizado, con varios frentes y con un proyecto político específico. Dicho proyecto pasó por varias etapas que constituyen su ideología política. Hasta los 60 su principal objetivo era luchar por una reforma agraria e indemnizaciones para campesinos desplazados. Luego, se enfocaron en acabar la desigualdad social, política y económica del país, influenciados por dos grandes ideologías del mundo. El marxismo-leninismo que dominó hasta comienzos de los 90 y que confía en el poder militar para la consecución de sus metas, por esto su lema era: "El poder nace del fusil". Asimismo, el bolivarianismo, que llega tras la caída de la URSS e infunde nuevas ideas, como el antiimperialismo, latinoamericanismo, militarismo e intervencionismo económico. De igual forma, han ido adoptando posiciones manifestadas por la opinión pública tales como el anticlientelismo, la denuncia de prácticas corruptas en el gobierno y de injusticias sociales y la búsqueda por una democracia más participativa (PNUD, 2003).

Para el cometido de todos sus propósitos el grupo armado decidió actuar por medio de actos de terror, secuestros y asesinatos. Por esta razón, a través de los años, el país ha sufrido con las diferentes expresiones de los frentes; las muertes, las luchas y las violaciones de los derechos humanos son incontables. Esto pone de manifiesto cómo la toma del poder puede llegar a sobrepasar los límites de la ética, acabando con la vida de miles de seres humanos; unos involucrados en la contienda y otros, civiles inocentes que terminan convertidos en medios para lograr un fin. En esta línea, las mujeres guerrilleras reclutadas forzosamente sufren múltiples violaciones de 
sus derechos humanos básicos. Dentro de los frentes estas son concebidas como un combatiente más, a excepción de aquellas que ocupan altos mandos. Deben cumplir con labores de cocina y limpieza, al igual que los hombres, pero también son objeto de los deseos sexuales de estos. A pesar de querer combatir con los estereotipos tradicionales, el grupo revolucionario falla en cuanto a la sexualidad y las relaciones sentimentales de las mujeres. Por supuesto están las que son respetadas como cualquier otro comandante, pero generalmente las niñas y mujeres que son reclutadas a la fuerza y no tienen cargos importantes son violadas, abusas, se convierten en compañeras sexuales de turno y son obligadas a abortar en condiciones inhumanas. De esta forma la cosmovisión de las mujeres guerrilleras transgrede la autonomía y el valor de la mujer, reduciéndolas en muchos casos a sirvientas o esclavas sexuales. A diario se enfrentan con actos de violencia sexual, torturas, castigos y abortos forzados; actos que no sólo demuestran la falta de ética y conciencia por la dignidad de la mujer, sino que representan también los daños e injusticias sociales que estas viven y que inicialmente las FARC "condenaban" en su discurso.

\section{La vida de las mujeres reclutadas forzosamente}

Muchas mujeres han sido reclutadas a la fuerza cuando los guerrilleros van de pueblo en pueblo buscando nuevos miembros y gran parte de ellas son menores de edad que son amenazadas (y a sus familias) y forzadas a unirse. De hecho, estudios realizados por la Inteligencia de la Policía muestran que cada frente debe cumplir con una cuota de mujeres reclutadas que deben tener entre 13 y 15 años (Bedoya, 2011). Así lo demuestra el relato de una joven que pasó 9 años en los frentes de las FARC y que fue reclutada cuando apenas tenía 7 años. Adriana ${ }^{3}$ cuenta que los guerrilleros llegaron a su casa por su hermano, pero al conocer que sufría de epilepsia se la llevaron a ella y sólo le permitieron empacar una muda de ropa para llevar. Los primeros años fueron dolorosos, pero con el tiempo acabó acostumbrándose a ese estilo de vida y en una época le encargaron el reclutamiento de menores. Así como un día se la llevaron a ella de su hogar, ahora era ella quien separaba a los niños y niñas de sus familias, y debía cumplir con tres menores cada semana, por órdenes de su comandante (Sarralde, 2015). 
Dentro los bloques, una vez reclutadas generalmente las mujeres son las encargadas de la cocina y deben atender a los militares en sus necesidades; incluyendo sus deseos sexuales. Constantemente son objeto de violación sexual y cuando quedan embarazadas deben realizarse abortos forzados. De acuerdo al periódico El Tiempo, dentro de 112 mujeres que se desmovilizaron en la primera mitad del 2011, 57 lo hicieron para buscar a hijos que tuvieron en el monte y fueron obligadas a regalar. Además, se estima que cerca del $80 \%$ de estas mujeres han sufrido uno o más abortos inducidos (Bedoya, 2011).

No obstante, aunque las cifras son aterradoras y permiten tener un panorama de las víctimas; más allá de los números, el impacto que ha tenido la guerra sobre las mujeres se materializa en los múltiples daños físicos, psicológicos y morales que atentan su integridad y afectan la forma en que se relacionan, su visión del mundo y la concepción de sí mismas. Nadie está preparado para enfrentar las imágenes de los heridos y muertos tras combates, o el asesinato de alguna de sus compañeras como medio de castigo, y muchos menos, los maltratos o la pérdida de un hijo. Todo esto forma un cúmulo de sentimientos encontrados de rabia, odio, dolor, vergüenza, miedo, culpa, venganza y tristeza, que no es fácil confrontar y que vuelve frágil emocionalmente a quienes enfrentan esta situación.

En este sentido, la vida en la guerra es un mundo tan complejo que se encuentra regido por la incertidumbre y el miedo, y esto por supuesto trae consigo repercusiones psicológicas y emocionales en aquellos que lo experimentan. Las mujeres son especialmente vulnerables a esto; ellas, objeto de torturas y agresiones sexuales viven en medio de circunstancias traumáticas que alteran el sentido que tenían de la vida. De hecho, el Centro Nacional de Memoria Histórica expone en su informe ¡Basta Ya! que "Algunas de las huellas e impactos psicológicos causados por la violencia son: el encierro, el aislamiento, el silencio, las pesadillas recurrentes y repetitivas, la pérdida del deseo sexual, el deterioro de la autoestima, y sentimientos depresivos." (CNMH, 2013: 268).

La imposibilidad de tener hijos por las políticas de planificación y el aborto en caso de embarazo, además de ser un daño, es una violación de los derechos humanos puesto que atenta con la integridad y la libertad de las mujeres, y las deja con traumas y daños psicológicos. Ellas son obligadas a someterse a abortos realizados en condiciones inhumanas por enfermeros empíricos de la guerrilla, y si se oponen a esto corren el riesgo del veredicto del Consejo de Guerra: ser fusiladas o tener que realizar trabajos que requieren 
mucha fuerza para que pierdan el bebé. Así lo confirma la comandante del frente 47 de las FARC, Elda Neyis Mosquera, alias Karina, quien es una muestra de las mujeres en calidad de victimarias y quien admitió haber participado en las operaciones de aborto de tres de sus subordinadas, las cuales "quedaban con serios problemas psicológicos." (Laverde, 2013)

En esta misma línea, las mujeres también son víctimas de daños morales, entendiendo estos como el deterioro de valores significativos para las personas y comunidades (CNMH, 2013: 268); es violentar y degradar aquellos valores asumidos, que hacen parte de la identidad tanto colectiva como individual. Sin embargo, no sólo los valores personales se ven afectados, también existe daño moral en la imagen preconcebida de los actores involucrados que estigmatiza el rol de las mujeres. Muchas de ellas son señaladas como prostitutas y discriminadas en la cotidianidad, cosa que ha perjudicado su reinserción tras desmovilizarse.

Hoy en día, existen un sinnúmero de testimonios que exhiben la cruda realidad de las mujeres reclutadas y los desafíos que enfrentan. Por ejemplo, en el Guaviare el frente 39 es famoso por su jefe, conocido como "Cadete", quien abusa de las mujeres de forma exagerada. Ellas no tienen libertad para escoger un compañero, ya que él las usa a todas. Esto lo constata una de ellas, Martha ${ }^{4}$, quien fue obligada a abortar en cuatro ocasiones y "Walter", un guerrillero desmovilizado que da testimonio de los atropellos cometidos por su comandante y dice haberse retirado después de 20 años de servicio por las injusticias que lo rodeaban (Bedoya, 2011).

Del mismo modo, Adriana, aquella joven que debía reclutar nuevos integrantes, cuenta que su vida en las FARC cambió con la muerte de su mejor amiga. Relata que su amiga al quedar embarazada y conocer que en la guerrilla su única opción era abortar, decidió escaparse. Lo logró, pero tres meses después de haber tenido a su bebe la encontraron y un Consejo de Guerra la condenó a muerte. El comandante designó a Adriana para hacerlo, y al respecto dice: "Tuve que matarla y fue algo que me dolió muchísimo. Después de eso no volví a ser la misma y ya nada en la guerrilla fue igual" (Sarralde, 2015). Esta experiencia de vida, presenta una clara imagen de los daños psicológicos que la guerra puede generar, 
el hecho de matar a un ser querido es una situación traumática que repercute en la vida de cualquier ser humano. En efecto, Adriana necesitó de ayuda psicológica y tratamiento con psiquiatras para poder adaptarse a una nueva vida civil a sus 20 años.

Asimismo, una guerrillera de 27 años quedó embarazada en 2010 e intentó ocultar su situación para poder tener su bebé, pero cuando tenía 6 meses de gestación su barriga ya era evidente y la obligaron a abortar. "Me obligaron a tomar 50 pastillas y llamaron a una enfermera para que me sacara el feto. Me empezaron a medicar a las 9:00 a. m. Tuve mucho dolor, contracciones, vómito. Solo pude expulsar al bebé muerto a las 11:30 p. m." cuenta la joven (Sarralde, 2015). Esto constata las terribles condiciones en las que las mujeres son presionadas a abortar, incluso llegando a poner en peligro sus vidas por medio de prácticas irresponsables y el exceso de fuertes medicamentos.

\section{Más allá de los abusos, los problemas éticos de fondo}

Todas estas historias y vivencias de algunas mujeres encarnan la situación de maltrato y abuso que viven la mayoría de ellas en los frentes de las FARC. Situación que demuestra los daños morales, físicos y psicológicos; y la violación de los derechos humanos que sufren las mujeres, lo cual las delimita como víctimas del conflicto armado. Víctimas no sólo de abusos físicos sino también de todo un atentado contra su dignidad como seres humanos. Estas mujeres que han sido forzadas a vivir en medio del terror, lamentablemente no tuvieron elección y les tocó aceptar ser sirvientas y esclavas sexuales; encerradas en la selva sin potestad alguna sobre su libertad, su cuerpo, sus deseos, o su dignidad. En este sentido, su vida ha sido arrebatada, pues ellas no pidieron estar ahí y no tienen más opción que seguir órdenes de sus superiores y aceptar su realidad. Así, al perder toda autonomía sobre su vida y sus decisiones, su ser ético es destruido, quedando reducidas a ser medios o instrumentos para suplir las necesidades de otros. ¿Y sus necesidades?; la cuestión va más allá de los abusos, puesto que ellas dejaron de ser dueñas de su vida en el momento en que entraron en el monte.

"Todos los seres humanos nacen libres e iguales en dignidad y derechos y, dotados como están de razón y conciencia, deben comportarse fraternalmente los unos con los otros", así dicta el primer artículo de la Declaración Universal de los Derechos Humanos de 1948. Esto por supuesto no se cumple para las mujeres reclutadas, 
quienes son prueba de la falta de ética que aún impera en la guerrilla y en la sociedad. Por un lado porque no poseen igualdad en dignidad, por el otro porque sus derechos humanos más básicos son violados y, además, porque de ninguna manera los guerrilleros se están "comportando fraternalmente" con las mujeres. Lo anterior permite cuestionarse sobre el verdadero avance de la sociedad en materia de derechos, ética y respeto por el otro, es decir, ¿hasta qué punto puede una persona interferir en la vida de otra, someterla a atroces condiciones de vida y obligarla a actuar en contra de su voluntad? En el caso de las mujeres reclutadas forzosamente es evidente que el desarrollo de su integridad y su proyecto de vida ${ }^{5}$ estuvo totalmente interceptado por los guerrilleros, y esto crea un conflicto ético-moral que acaba con la dignidad, libertad y existencia de la mujer; no sólo porque quedan privadas de su derecho a elegir y auto determinarse o porque son víctimas de abusos sexuales y transgresión de sus derechos humanos, sino porque su vida ha sido dictaminada por otro. Todos estos derechos propios del ser humano se acaban cuando ya no se es dueño de sí, cuando ellas se convierten en herramientas de otro y son obligadas a realizar actos que atenta con la vida de otras personas en contra de su voluntad.

De ahí que, la situación de estas mujeres también constituya un problema ético en términos de su libre albedrío siendo coaccionado, debido a las denominadas 'zonas grises' en las que se da una dicotomía entre lo que se quiere hacer y lo que se debe hacer, o en su defecto es obligado a hacer. En efecto, de acuerdo a la investigación de Viridiana Molinares, "La zona gris constituye el espacio donde transcurre la experiencia humana, en el que se puede explorar la fusión y alteración entre víctimas y verdugos; y que revela un fracaso ante la determinación de responsabilidad y culpa jurídicas" (Molinares, 2012: 9). Esto se ve evidenciado en las mujeres reclutadas forzosamente cuando se ven obligadas a ser partícipes de actos terroristas y a realizar acciones con las que probablemente están en desacuerdo por sus principios morales o porque las consideran inhumanas. Su libertad y su autonomía es destruida, lo cual las introduce en una zona gris, donde su ser ético es aniquilado y su dignidad vulnerada. En este sentido, estas zonas son un dilema ético para estas mujeres que no tuvieron la

5 Se refiere al trastorno del proyecto de vida cuando "[...] se interfiere en el destino del sujeto, frustrando, menoscabando o postergando su realización personal”. (Zavala de González, 2005) 
opción de elegir sus vidas, pues las pone en una posición incómoda entre lo que tienen que hacer y lo que quieren hacer. Un claro ejemplo de esto es el caso mencionado de Adriana, quien fue obligada a matar a su mejor amiga por oponerse a abortar y con esto hacer algo que no deseaba. Aquí vuelve a jugar entonces la ética por el otro, por su dignidad y su libertad. Las mujeres son forzadas a entrar en este grupo terrorista, son violadas, abusadas y obligadas a matar personas (incluso sus compañeras) y abortar a sus bebés en condiciones atroces y con métodos riesgosos. Así pues, ¿cómo se debería juzgar los actos de estas mujeres? Muchas son tildadas prostitutas y estigmatizadas como unas guerrilleras más que aceptan ese estilo de vida, pero en realidad en su interior hay conflictos éticos, traumas, daños psicológicos, miedo, sentimientos encontrados, culpa y confusión. Les tocó vivir esta vida y le tocó cometer actos terribles, y eso debe ser aceptado y comprendido por la sociedad civil.

De igual forma, la situación de estas mujeres expone además las contradicciones en la vida de las FARC. Si nos devolvemos en el tiempo, recordaremos que la guerrilla empezó como campesinos que deciden armarse para defenderse y posteriormente luchar por la igualdad social en el país, sin embargo, esto se ha perdido y hoy en día no se ve en la cotidianidad de la guerrilla. A pesar de que llevan más de 50 años en el país, sus acciones no concuerdan con aquello que promocionan, pues las decisiones de los integrantes de este grupo guerrillero no están siendo consecuentes con los valores éticos y morales esperados por la sociedad. ¿Dónde queda entonces el impulso de hacer justicia y acabar con las irregularidades del gobierno? La realidad es que la violencia sexual hacia las mujeres en las filas de las FARC, conocido como uno 'de los capítulos criminales más silenciosos del conflicto en Colombia', expone contradicciones éticas en su ideología política. La concepción de la mujer como un combatiente más y a su vez como compañera sexual, objeto de violaciones, demuestra inconsistencias en la cosmovisión del grupo guerrillero. Por un lado proclaman ser el 'ejército del pueblo', aquel que pretender defender a los campesinos y los pobres de los abusos del gobierno, aquel que desea acabar con la desigualdad social y la corrupción. Por otro lado, son precursores de abusos contra niños y mujeres, y promotores de desigualdad entre sus miembros, es especial contra las mujeres que continúan siendo discriminadas por su condición misma de mujer y que deja expuesto la persistencia del machismo y el 
patriarcado. Así, la contradicción radica en promover una lucha en pro de la igualdad social y dentro de su misma organización abusar, coaccionar y violar a las mujeres tanto sexualmente como éticamente, en el sentido de aniquilar su libertad y autonomía. ¿Dónde queda entonces la lucha por la igualdad social? Al parecer se perdió en el camino, pues es claro que sus propósitos iniciales ya no tiene ningún fundamento; ya los secuestros y las injusticias demuestran su falta de ética y respeto con la vida de las personas. Defender los derechos, promover la igualdad y acabar con la injusticia no es precisamente abusar, maltratar, discriminar y agredir a las mujeres.

\section{Conclusiones}

En conclusión, hoy en día, en medio de un proceso de paz como el que atraviesa el país en busca de solucionar y terminar con el conflicto armado más largo de América Latina, todos estos dilemas éticos deben tenerse en cuenta en orden de abarcar las múltiples caras del conflicto. La violencia cometida contra la mujer en espacios de guerra es una evidente violación de los derechos humanos internacionales que atenta la dignidad, identidad e integridad de estas mujeres que han sido obligadas a vivir condicionadas por las reglas de los frentes. De ahí que las Naciones Unidas, en la resolución de 1889 del Consejo de Seguridad insten a la participación de las mujeres en los procesos de paz (CNRR-Grupo de Memoria Histórica, 2011). Lo cual nos deja con una reflexión sobre la importancia de las mujeres en los diálogos que actualmente se adelantan en La Habana, desde su posición tanto de víctimas como de victimarias, no sólo para superar los desafíos éticos expuestos sino como agentes de cambio que propicien una verdadera transformación en aras de conseguir un posconflicto exitoso. La marginalización de la mujer guerrillera en este proceso no es una opción, de hecho, exigirle a la guerrilla que responda por las violaciones de los derechos humanos de las mujeres y las formas de violencia sexual cometidas durante más de una década es uno de los grandes retos que enfrentan las negociaciones.

Sin embargo, los desafíos no terminan allí; ahora durante el proceso de paz uno de los más grandes retos que el posconflicto debe superar es la reinserción de aquellos que fueron víctimas de la guerra, que perpetuaron la guerra y los que fueron obligados a hacerlo. La sociedad civil debe enfrentarse al hecho de tolerar y aceptar a estas mujeres 
cuya experiencia de vida ha estado marcada por el atropello y la guerra. Aprender que fueron unas victimas más del conflicto que ahora tienen el gran reto de volver a la vida civil cuando su realidad era la de las violaciones y los abortos. Entender que su proyecto de vida fue totalmente trastornado y coaccionado; que fueron obligadas a cometer actos terribles y por ende no estigmatizarlas como guerrilleras, victimarias o prostitutas. Así pues, la ética de cada uno de nosotros como colombianos también entra a colación, nuestra conducta y nuestra actitud frente a esta nueva ola social que se avecina son claves para lograr un país en paz. El reto no es sólo sobre ¿Cómo juzgar a un niño o niña que fue reclutado de pequeño, y a quien se le exigió cometer actos violentos en contra de su voluntad? La paz también implica la actitud de cada persona y su postura hacia estas víctimas y actores de la guerra. Estas y más cuestiones son necesarias para pensar críticamente el rol de la mujer guerrillera e interrogar su participación y relevancia en el actual proceso para alcanzar paz.

\section{Bibliografía}

BEDOYA, Jineth. (2011) "Asi es la dramática vida de las mujeres en las Farc". En: ElTiempo.com. Consultado el 30 de septiembre de 2015, desde http://www.eltiempo. com/archivo/documento/CMS-9598605.

CENTRO NACIONAL DE MEMORIA HISTÓRICA. (2013) ;Basta Ya! Colombia: memorias de guerra y dignidad. Bogotá D.C., Colombia: Pro-Off set Editorial S.A.

COHEN, Diana. (2011). Inteligencia ética para la vida cotidiana. Buenos Aires, Argentina: Editorial Sudamericana.

CORTINA, Adela. (200). Ética Minima: Introducción a la Filosofía Práctica. Madrid, España: Editorial Tecnos, S.A.

Grupo de Memoria Histórica de la Comisión Nacional de Reparación y Reconciliación. (2011). La Memoria Histórica Desde La Perspectiva De Género Conceptos Y Herramientas. Bogotá D.C., Colombia: Pro-Offset Editorial S. A.

Grupo de Memoria Histórica de la Comisión Nacional de Reparación y Reconciliación. (2011). Mujeres y guerra: Victimas y resistentes en el Caribe colombiano. Bogotá D.C., Colombia: Editora Aguilar, Altea, Taurus, Alfaguara, S. A.

HERNÁNDEZ, Miranda. (2011). "La miserable vida de las mujeres en las Farc” En: 
ElMundo.es. Consultado el 26 de septiembre de 2015, desde http://www.elmundo.es/ america/2011/03/09/colombia/1299687650.html.

HOYOS, Maria Paula. (2013). "El papel de las mujeres en la guerra”. En: Lasillavacia.com. Consultado el 2 de octubre de 2015, desde http://lasillavacia.com/historiainvitado/41299/mariaholes/el-papel-de-las-mujeres-en-la-guerra.

LAVERDE, Juan David. (2013). "Así obligan a las mujeres a abortar en las Farc". En: El Espectador. Consultado el 2 de octubre de 2015, desde http://www.elespectador. com/noticias/judicial/asi-obligan-mujeres-abortar-farc-articulo-401836.

MOLANO, Alfredo. (2015). Fragmentos de la historia del conflicto armado (19202010). En: Comisión Histórica del Conflicto y sus Víctimas (Comp.). Contribución al entendimiento del conflicto armado en Colombia (pp. 540 - 598). Bogotá D.C., Colombia: Espacio Crítico.

MOLINARES, Viridiana. (2012). "El conflicto entre el derecho y una nueva ética no explorada: Presentación desde el concepto de zona gris.", Revista de Derecho, Universidad del Norte, Edición especial: 1-17, Barranquilla, Colombia.

NACIÓN. (2015). “División en la Fiscalía por culpabilidad de guerrillera”. En: Semana.com. Consultado el 2 de octubre de 2015, desde http:/www.semana.com/nacion/ articulo/division-en-la-fiscalia-por-culpabilidad-de-guerrillera/444614-3

NACIONES UNIDAS. (1948) Declaración Universal de los Derechos Humanos. Consultado el 2 de octubre de 2015, desde http://www.un.org/es/documents/udhr/

Programa de las Naciones Unidas para el Desarrollo - PNUD. (2003). El conflicto, callejón con salida. Informe Nacional de Desarrollo Humano para Colombia - 2003. Bogotá D.C., Colombia: Panamericana Formas e Impresos S. A.

REDACCIÓN JUDICIAL. (2015). "Las Farc y la violencia sexual". En: El Espectador. Consultado el 2 de octubre de 2015, desde http://www.elespectador.com/noticias/ judicial/farc-y-violencia-sexual-articulo-554120

SARRALDE, Milena. (2015) "El aterrador expediente de violencia sexual de las Farc". En: ElTiempo.com. Consultado el 2 de octubre de 2015, desde http://www.eltiempo.com/politica/justicia/delitos-sexuales-de-las-farc/15516882.

SARRALDE, Milena. (2015). “'Tenía que llevar a la guerrilla 3 niños por semana': menor reclutada". En: ElTiempo.com. Consultado el 30 de septiembre de 2015, desde http://www.eltiempo.com/politica/justicia/reclutamiento-de-menores-guerrilla-venia- 
por-mi-hermano-pero-me-llevo-a-mi/15240878.

ZAVALA DE GONZÁLEZ, Matilde. (2005) "Daño a proyectos de vida", cit. RRC y S Año 2005-VII No. 4, abril 2005-1. 